Original Artikel

Received August 2020 / Revised September 2020 / Accepted October 2020

Spizaetus: Jurnal Biologi dan Pendidikan Biologi

\title{
Penyusunan Media Pembelajaran Biologi Berbasis Web pada Materi Animalia Sub Materi Nematoda dan Annelida bagi Siswa SMA Kelas X
}

\section{The Making Up of Web-Based Biology Learning Media on Animalia Subject: Nematoda and Annelida for $10^{\text {th }}$ Grade Senior High School}

\author{
Maria Patrisia Ivonie Babang
}

SD Negeri Wee Kapulota, Wali Ate - Sumba Barat Daya, 87253, Indonesia

Email: ivonedacunha87@gmail.com

\begin{abstract}
Abstrak. Penelitian ini bertujuan untuk menghasilkan sebuah produk pembelajaran biologi berbasis web dengan situs www.nematoda-annelida.com. Dari web pembelajaran Biologi yang disusun ini diharapkan dapat membantu siswa untuk memperoleh sumber belajar yang berkualitas. Penelitian ini merupakan sebuah langkah awal dari penelitian dan pengembangan (research and development). Penysunan website ini dilakukan melalui tahap: pendahuluan, pengembangan, produksi, kemudian divalidasi oleh ahli materi dan media. Subyek penelitian adalah siswa SMA kelas $X$ yang sedang menempuh materi Animalia dengan data yang diperoleh melalui kuesioner dan wawancara. Hasil penelitian dari ahli media adalah sangat baik dengan rerata skor 4,51. Sedangkan persepsi siswa terhadap web ini adalah sangat tinggi dengan rerata skor 3,27.
\end{abstract}

Kata Kunci: Animalia; Annelida; Nematoda; Penyusunan; Web

\section{Pendahuluan}

Mata Pelajaran Biologi adalah mata pelajaran yang mempunyai obyek kajian berupa makhluk hidup dan dapat ditangkap indera, dikembangkan berdasarkan pengalaman empiris (pengalaman nyata), memiliki langkahlangkah sistematis yang bersifat baku (Pusat Kurikulum, Balitbang Depdiknas: 2003: 7). Namun, ada beberapa kendala yang mempengaruhi pembelajaran Biologi di kelas, terkait dengan masalah ketersediaan dan pemanfaatan media pembelajaran di sekolah. Pertama, ketersediaan media pembelajaran yang masih belum merata di berbagai sekolah. Ada yang menggunakan media pembelajaran secara maksimal tetapi ada juga yang menggunakan secara minimal. Media yang paling sering digunakan oleh guru adalah media cetak dan media sederhana yang tetap banyak dimanfaatkan oleh guru adalah papan tulis. Media audio visual dan media elektronik masih belum dimanfaatkan secara intensif. Sedangkan pemanfaatan dan penggunaan multimedia pembelajaran dalam berbentuk website pembelajaran pun belum diterapkan dalam proses pembelajaran di sekolah.

Kedua, pemanfaatan media. Media cetak merupakan media yang paling sering digunakan oleh guru, karena media ini paling mudah 
didapatkan. Namun, kebanyakan media cetak sangat bergantung pada katakata yang bersifat sangat abstrak, sehingga menuntut kemampuan abtraksi yang tinggi dari siswa. Oleh sebab itu perlu adanya pemilihan media pembelajaran yang disesuaikan dengan kompetensi yang akan dicapai, karakteristik bidang ilmu, kondisi guru dan siswa, akses siswa, biaya, proses pembelajaran yang akan dilaksanakan, organisasi, serta sistem pendukung. Pemanfaatan media pembelajaran perlu dioptimalkan, tidak terbatas hanya sebagai alat penyaji informasi keilmuan dan pengumpulan informasi, tetapi juga berfokus pada alat bantu untuk berinteraksi dan berkomunikasi. Media pembelajaran dapat mempermudah siswa untuk belajar.

Salah satu media yang tepat dan dapat dapat digunakan dengan baik dalam mempermudah proses pembelajaran biologi adalah berupa website pembelajaran. Melalui website pembelajaran ini, siswa diharapkan dapat belajar dengan aktif, interaktif

\section{Metode}

Jenis penelitian ini adalah penelitian dan pengembangan yang berorientasi pada produk yang dikembangkan yaitu berupa website pembelajaran untuk mata pelajaran Biologi sub materi Nematoda dan Anellida bagi siswa SMA kelas X. Dalam bukunya Anik Gufron menyebutkan bahwa prosedur pengembangan dimulai dengan pendahuluan/perencanaan,

pengembangan, uji coba dan diseminasi. Penelitian ini dilaksanakan di SMA Negeri 9 Yogyakarta, dengan waktu pelaksanaan pada bulan Februari-Maret 2010. Instrumen penelitian yang dipergunakan dalam penelitian ini lembar kuesioner. sehingga dapat meningkatkan prestasi belajarnya. Selain itu penggunaan website pembelajaran ini memungkinkan siswa belajar sesuai dengan kemampuan dan kecepatan dalam memahami pengetahuan dan informasi yang ditayangkan, sehingga dapat membuat siswa melakukan kontrol terhadap aktifitas belajarnya. Disamping itu, website pembelajaran ini ini dapat diprogram agar mampu memberikan umpan balik terhadap hasil belajar dan memberikan pengukuhan terhadap prestasi belajar siswa. Website pembelajaran ini juga dapat diprogram untuk memeriksa dan memberikan skor hasil belajar secara otomatis (Yusuf :2008).

Tujuan dari penelitian ini adalah untuk menghasilkan sebuah media pembelajaran biologi berbasis web pada materi Animalia sub materi Nematoda dan Annelida sesuai dengan tahapan-tahapan pengembangan yang tepat sehingga menghasilkan multimedia pembelajaran yang berkualitas.

Teknik analisis data kualitatif berupa pernyataan benar atau salah untuk aspek kebenaran konsep yang disajikan dalam website pembelajaran yang sedang dikembangkan yang diberikan oleh Ahli Materi. Data dari Ahli Media akan dianalisis menggunakan analisis statistik deskriptif, berupa pernyataan sangat kurang dengan skor 1 , kurang dengan skor 2 , cukup dengan skor 3 , baik dengan skor 4 , sangat baik dengan skor 5 , yang kemudian diubah dalam data kuantitatif dengan skala 5 yaitu penskoran dari angka 1 sampai angka 5. 
Tabel 1. Kriteria Penilaian

\begin{tabular}{cccc}
\hline No & Kriteria & Rumus & Perhitungan \\
\hline 1 & Sangat Baik & $\mathrm{X}>\mathrm{Xi}+1,8 \mathrm{Sbi}$ & $\mathrm{X}>4,21$ \\
2 & Baik & $\mathrm{Xi}+0,61 \mathrm{Sbi}<\mathrm{X} \leq \mathrm{Xi}+1,8 \mathrm{Sbi}$ & $3,40<\mathrm{X} \leq 4,21$ \\
3 & Cukup & $\mathrm{Xi}-0,61 \mathrm{Sbi}<\mathrm{X} \leq \mathrm{Xi}+0,6 \mathrm{Sbi}$ & $2,60<\mathrm{X} \leq 3,40$ \\
4 & Kurang & $\mathrm{Xi}-1,8 \mathrm{Sbi}<\mathrm{X} \leq \mathrm{Xi}+0,6 \mathrm{Sbi}$ & $1,79<\mathrm{X} \leq 2,60$ \\
5 & Sangat Kurang & $\mathrm{X} \leq \mathrm{Xi}-1,8 \mathrm{Sbi}$ & $\mathrm{X} \leq 1,79$ \\
\hline
\end{tabular}

\section{Hasil dan Pembahasan}

Berdasarkan hasil validasi Ahli Media terhadap Kualitas Produk yang dihasilkan dapat dikatakan bahwa kualitas produk yang dihasilkan adalah sangat baik, yang dapat dilihat pada Tabel 2. Adapun hasil persepsi siswa terhadap produk yang dihasilkan yaitu sangat baik yang dapat dilihat pada Gambar 1.

Kualitas multimedia pembelajaran interkatif ini termasuk dalam kriteria baik dan sangat baik. Pernyataan tersebut dapat dibuktikan dan hasil analisis penelitian " baik" oleh ahli materi dan "sangat baik" oleh ahli media dan hasil persepsi yang "sangat tinggi" oleh siswa uji coba. Melalui hasil ini dapat diketahui bahwa website pemebaljaaran ini sangat baik jika digunakan dalam proses pembelajaran di kelas dan diharapkan produk ini bisa dikembangkan untuk mata pelajaran lain yang ada. Hasil ini didukung oleh penelitian yang dilakukan oleh Kuswanto (2018), dari hasil penelitiannya yang berjudul "Media Pembelajaran Berbasis Web pada mata pelajaran Biologi kelas $\mathrm{X}$ menunjukan bahwa media pembelajaran berbasis web yang dikembangkan pada mata pelajaran Biologi kelas $X$ sudah layak untuk digunakan dalam pembelajaran di sekolah.

Tabel 2. Kualitas Produk Website Pembelajaran Hasil Validasi Ahli Media

\begin{tabular}{ccl}
\hline Aspek Penilaian & Rerata Skor & Kriteria \\
\hline Skor Tampilan & 4,62 & Sangat Baik \\
Skor Pemrograman & 4,40 & Sangat Baik \\
\hline Rerata & 4,51 & Sangat Baik \\
\hline
\end{tabular}

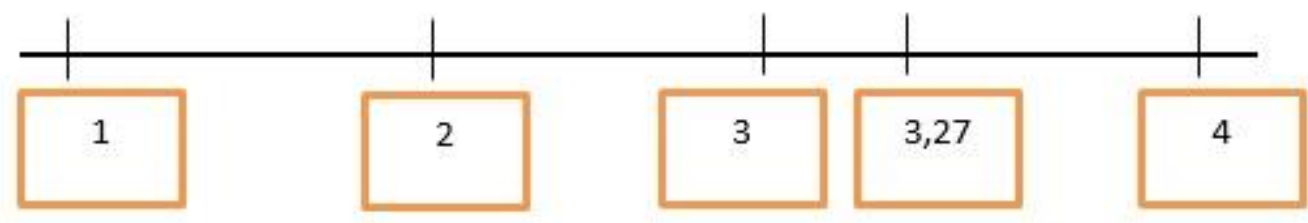

Gambar 1. Persepsi Siswa terhadap Produk Website 
Adapun beberapa hal yang menurut siswa menajdi kelebihan produk ini yaitu tampilan yang menarik, interaktif serta gambar dan video yang menunjang, serta materi yang disajikan secara menarik. Ketertarikan siswa terhadap sumber belajar merupakan gejala yang sangat baik untuk menuju

\section{Simpulan}

Berdasarkan hasil penelitian produk website pembelajaran, maka dapat disimpulkan bahwa kualitas website pembelajaran yang di kembangkan menurut penilaian dari ahli media menilai sangat baik dengan rerata skor keseluruhan yaitu 4,51, hal tersebut peningkatan hasil belajar yang lebih maksimal. Produk ini sangat memungkinkan siswa termotivasi untuk belajar secara aktif dan mandiri karena selain mudah digunakan, menurut siswa produk ini juga tidak membosankan karena penyajiannya yang menarik.

\section{Daftar Pustaka}

1. Gufron, Anik, Widyastuti Purbani dan Sri Sumarningsih. 2007. Panduan Penelitian dan Pengembangan. Yogyakarta : Lembaga Penelitian UNY.

2. Borg, W.R dan Meredith Damien Gall.1983. Educational research An Introduction. Fourth edition. New York : Longman.

3. Kuswanto, Joko. 2018. Media Pembelajaran Berbasis Web pada Mata Pelajaran Biologi Kelas $X$. Malang : IKIP Budi Utomo Malang

4. Pusat Kurikulum, Balitbang Depdiknas. 2003 .Standar Kompetensi dan Kompetensi Dasar Biologi. Jakarta: Depdiknas.

5. Yusuf, Taufika. 2008. Pengembangan Multimedia Pembelajaran Mata Kuliah Pendidikan Kesehatan Sekolah untuk Mahasiswa PJKR FIK UNY. Yogyakarta : FIK UNY 